\title{
New metrics for managing and sustaining the ocean's bounty
}

\author{
Heather Tallis ${ }^{\mathrm{a}, *}$, Sarah E. Lester ${ }^{\mathrm{b}}$, Mary Ruckelshaus ${ }^{\mathrm{c}}$, Mark Plummer ${ }^{\mathrm{c}}$, Karen McLeod ${ }^{\mathrm{d}}$, \\ Anne Guerry ${ }^{\mathrm{a}}$, Sandy Andelman ${ }^{\mathrm{e}}$, Margaret R. Caldwell ${ }^{\mathrm{f}}$, Marc Conte ${ }^{\mathrm{a}}$, Stephen Copps ${ }^{\mathrm{g}}$, \\ David Fox ${ }^{h}$, Rod Fujita ${ }^{i}$, Steven D. Gaines ${ }^{\mathrm{j}}$, Guy Gelfenbaum ${ }^{\mathrm{k}}$, Barry Gold ${ }^{\mathrm{l}}$, Peter Kareiva ${ }^{\mathrm{m}}$, \\ Choong-ki Kim ${ }^{a}$, Kai Lee ${ }^{n}$, Michael Papenfus ${ }^{a}$, Scott Redman ${ }^{\circ}$, Brian Silliman ${ }^{p}$, \\ Lisa Wainger ${ }^{\mathrm{q}}$, Crow White ${ }^{\mathrm{b}}$
}

\footnotetext{
a The Natural Capital Project, Woods Institute for the Environment, Stanford University, 371 Serra Mall, Stanford, CA 94305, USA

${ }^{\mathrm{b}}$ Marine Science Institute, University of California, Santa Barbara, CA 93016, USA

${ }^{c}$ NOAA Fisheries, Northwest Fisheries Science Center, 2725 Montlake Blvd. E., Seattle, WA 98112, USA

' Oregon State University, COMPASS, Department of Zoology, Corvallis, OR 97331-2914, USA

e Conservation International, 2011 Crystal Drive, Suite 500, Arlington, VA 22202, USA

${ }^{\mathrm{f}}$ Center for Ocean Solutions, Woods Institute for the Environment, Stanford University, Stanford, CA 94305, USA

${ }^{\mathrm{g}}$ National Marine Fisheries Service, 7600 Sand Point Way NE, Seattle, WA 98115, USA

h Oregon Department of Fish and Wildlife, Marine Resources Program, 2040 Southeast Marine Science Dr., Newport, OR 97365, USA

${ }^{i}$ Environmental Defense Fund, 123 Mission St. 28th Floor, San Francisco, CA 94105, USA

${ }^{\mathrm{j}}$ Bren School of Environmental Science and Management, University of California, Santa Barbara, CA 93106, USA

${ }^{\mathrm{k}}$ United States Geological Survey, 345 Middlefield Rd. MS 999, Menlo Park, CA 94025, USA

${ }^{1}$ Gordon and Betty Moore Foundation, 1661 Page Mill Rd., Palo Alto, CA 94304-1209, USA

${ }^{\mathrm{m}}$ The Nature Conservancy, 4722 Latona Ave NE, Seattle, WA 98105, USA

n David and Lucile Packard Foundation, 300 Second St., Los Altos, CA 94022, USA

${ }^{\circ}$ Puget Sound Partnership, P.O. Box 40900, Olympia, WA 98504, USA

${ }^{\mathrm{P}}$ Department of Biology, University of Florida, P.O. Box 118525, Gainesville, FL 32612, USA

${ }^{q}$ Center for Environmental Science, University of Maryland, 1 Williams St., Solomons, MD 20688, USA
}

\section{Introduction}

The oceans are a fount of natural wealth. They provide a rich bounty of goods and services ranging from seafood harvests and tourism opportunities to biological and chemical processes that regulate global climate. However, they are also heavily impacted by a host of human activities that are increasing in both scale and intensity. Society must quickly find ways to reconcile demands on the oceans with the natural limitations on their use. Marine

\footnotetext{
* Corresponding author at. Tel.: +1 6507237725 .

E-mail address: htallis@stanford.edu (H. Tallis).
}

\begin{abstract}
A B S T R A C T
Policies are arising around the world, most recently in the United States, that mandate the implementation of marine spatial planning as a practical pathway towards ecosystem-based management. In the new United States ocean policy, and several other cases around the globe, ecosystem services are at the core of marine spatial planning, but there is little guidance on how ecosystem services should be measured, making it hard to implement this new approach. A new framework is shown here for practical, rigorous ecosystem service measurement that highlights contributions from both natural and social systems. The novel three-step framework addresses traditional shortcomings of an ecosystem services approach by giving managers and scientists the tools to assess and track: (1) the condition of the ecosystem (supply metrics), (2) the amount of ocean resources actually used or enjoyed by people (service metrics), and (3) people's preference for that level of service (value metrics). This framework will allow real world progress on marine spatial planning to happen quickly, and with a greater chance for success.
\end{abstract}

spatial planning (MSP) promises a "world changing" solution for coordinating a broad range of ocean uses and guiding a new era of ocean management that is better suited to the increasingly complex pressures of the modern world [1]. To be efficient, MSP requires a comprehensive framework for not only considering a broad range of uses, but also measuring and tracking the suite of benefits people receive from the oceans, known as ecosystem services. Ecosystem services traditionally have been lumped into broad categories and measured in myriad ways. The lack of precision and established metrics stands as an impediment for decision-makers to set goals and measure success, making the implementation of this potentially powerful concept difficult at best. 
Presented here is a novel, three-step framework that addresses these traditional shortcomings of an ecosystem services approach. This framework provides guidance for identifying the specific ecosystem services to be considered in the design of MSP. It also provides managers and scientists involved in MSP the tools to assess and track (1) the condition of the ecosystem (supply metrics), (2) the amount of ocean resources actually used or enjoyed by people (service metrics), and (3) people's preference for that level of service (value metrics). For the first time, this framework will enable scientists to consistently measure services, assist policy makers in defining goals, and equip managers with tools to track progress towards these goals.

Providing ways to improve MSP comes at an opportune moment. On July 19, 2010, President Obama signed an executive order establishing a National Policy for the Stewardship of the Ocean, Coasts, and Great Lakes. The order adopts the final recommendations of the National Ocean Policy Task Force, a group with representatives from over 20 federal agencies that rarely collaborates on ocean issues, to develop a national ocean policy [2]. The Task Force's final recommendations [3] reiterate the consensus of the scientific and policy communities [4,5] by identifying implementation of ecosystem-based coastal and marine spatial planning as a priority objective, with the goal of sustaining the ecological goods and services people enjoy from oceans and coasts [3]. Ecosystem services as a framing concept can help smoothen the transition to MSP in several ways. First, ecosystem services explicitly include all benefits people receive from nature and so can provide a standard way of accounting for the human uses of and impacts on the ocean's natural resources. By accounting for ecosystem services, it is easier to readily reveal the effects of management actions and even natural patterns such as climate change that directly matter to people. Marine managers must often face tradeoffs among desirable goals, and so using an ecosystem services framework will make the decisions more transparent and more likely to lead to outcomes that benefit more people. Finally, it might even be possible to create new markets to capture the value of some of the ocean's ecosystem services. Incorporating these values into the market economy would help correct the lack of incentives to conserve ecosystem services and even encourage their supply. However, the market economy requires precision in identifying and measuring "products." The framework proposed here would serve this function and thus increase the prospects for the emergence of ecosystem service markets in the marine realm.

Below, a novel framework is presented for measuring ecosystem services. This framework provides a straightforward approach for comparing management options relative to many objectives, as well as a practical way to measure success for nature and people. Incorporation of these concepts in new ocean policies would help not only the US, but would also advance MSP efforts around the globe [6].

\section{Getting specific about services}

Ecosystem services are typically presented in broad terms, such as "recreation" or "coastal protection" [7], which are not specific enough for setting management objectives, measuring success, or assessing tradeoffs. The current approach to describing services is equivalent to writing "dairy products" on a grocery shopping list when you run out of milk. You could return from the market with a grocery bag full of cheese, butter, and sour cream but no milk, and still count the trip as a success. Writing "milk" on the list sets a much clearer goal, leaving options open for where and when to go shopping but only claiming success if milk is purchased. Similarly, the service of "recreation" actually encompasses many types of activities that vary significantly in their relation to ecological processes and their valuation by humans. Assessing the flow of "recreation" benefits from marine protected areas, for example, is crucially dependent on the exact set of recreation activities that take place. For example "recreation" in one MPA may largely consist of bird watching, while in another the major activities may be whale watching and diving. These activities are best measured and tracked using different metrics. Similarly, "coastal protection" actually encompasses many types of processes-e.g., wave and surge dampening by coastal vegetation that mitigates erosion or the accretion of sand by dune grasses that mitigates inundation. Which should be measured to assess the ecosystem service of "coastal protection"? Precise definitions ensure more complete accounting of all services because the current approach bundles many services into one. Although unbundling these services and defining them more precisely lack brevity, they actually make metric selection and assessment processes easier, clearer, and more complete. Time and resource limitations will require the selection of a subset of services for assessment or monitoring, but clearly defining those services chosen makes the selection of metrics much more straightforward and likely much more informative. The scientific community should focus future efforts on creating guidelines for prioritizing services and selecting metrics when time and resources are scarce.

\section{Moving beyond the supply side}

In addition to creating a refined classification of ecosystem services, this approach stresses the importance of measuring services at three distinct points along the production chain: supply, service, and value (Fig. 1). Many studies claim to measure ecosystem services, but in reality, they measure or discuss only supply, the first point. Ecosystem supply is the full potential of ecological functions or biophysical elements in an ecosystem to provide a potential ecosystem service, irrespective of whether humans actually use or value that function or element currently. For example, wave dampening by habitats such as mangroves, kelps (for example, in San Francisco Bay, insert in Fig. 2a; Fig. 2c),

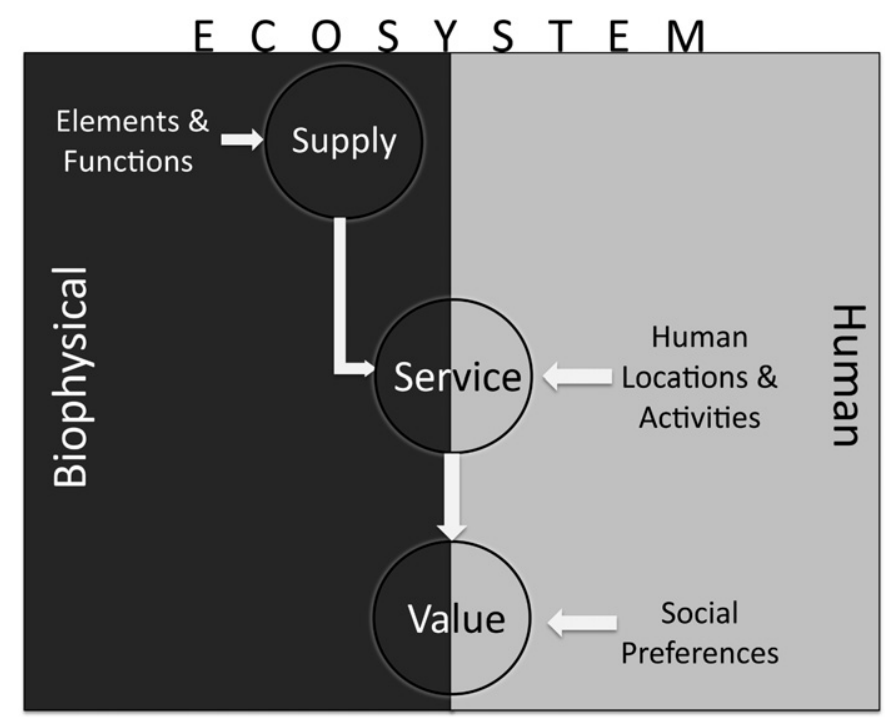

Fig. 1. Three measurement points for ecosystem services. Supply metrics deal only with the biophysical system underpinning the service of interest. Service metrics include critical information linking supply to beneficiaries. Value metrics weight the level of service based on people's preferences or social policy goals. 


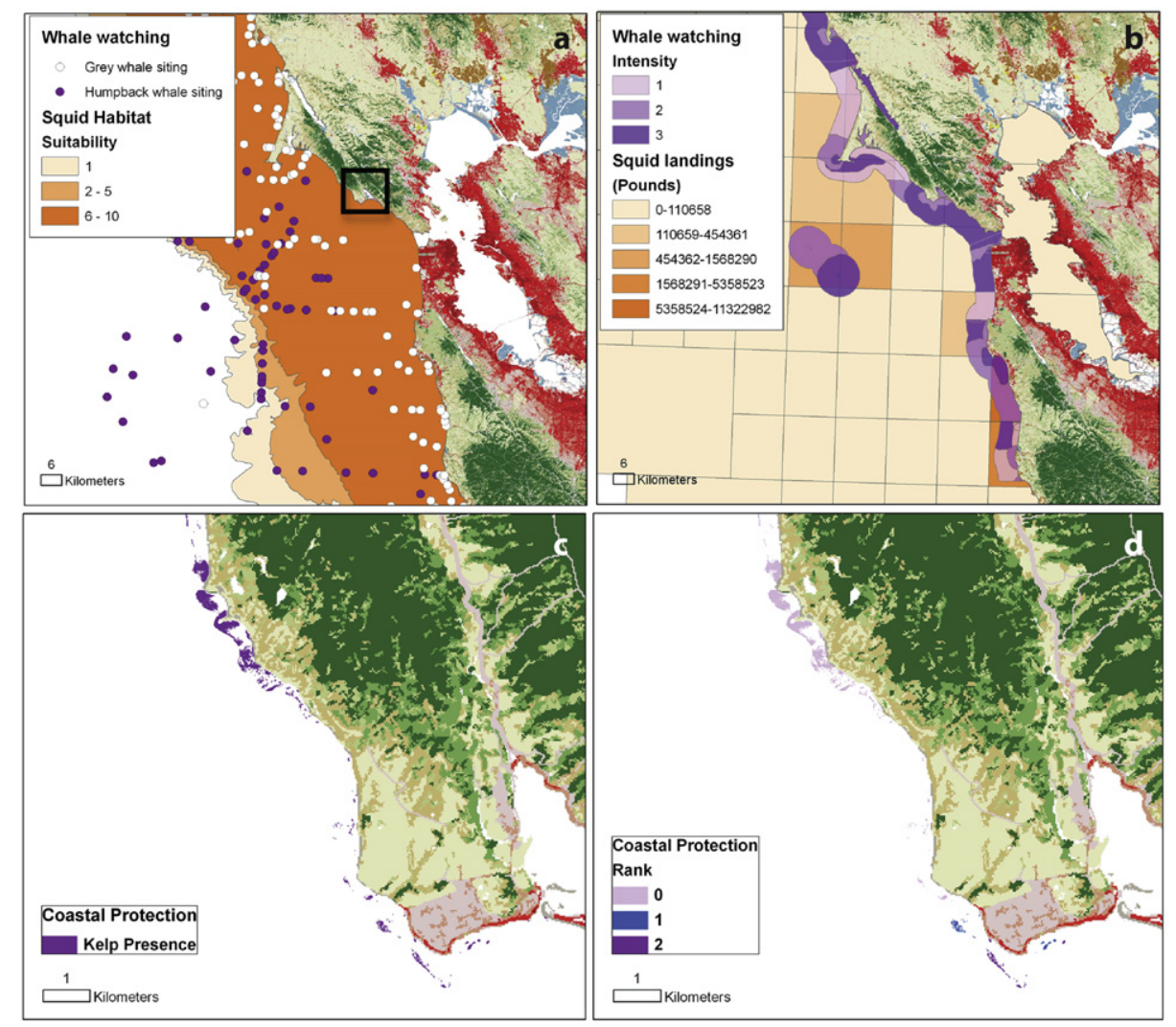

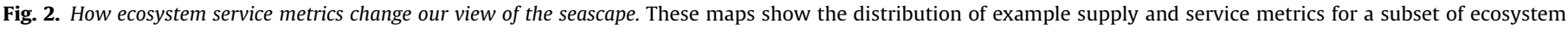

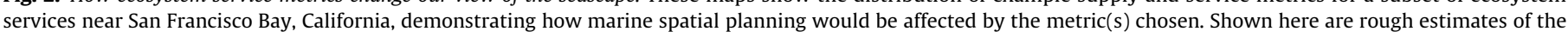

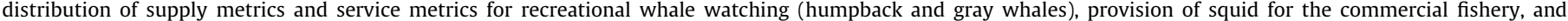

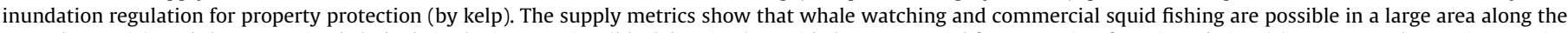

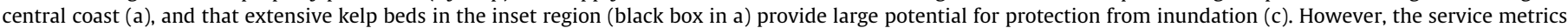

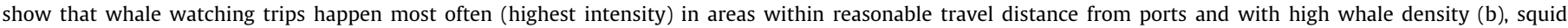

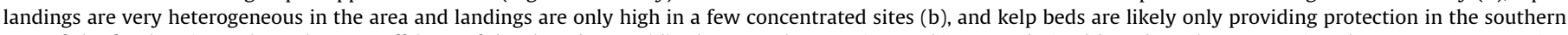

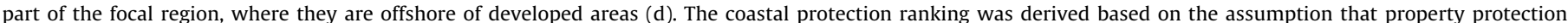

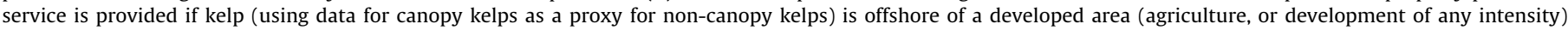

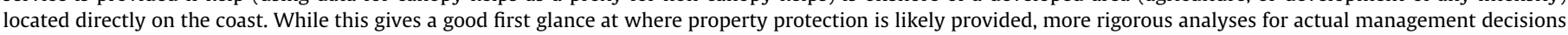

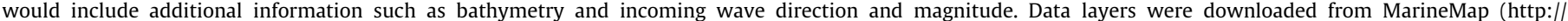

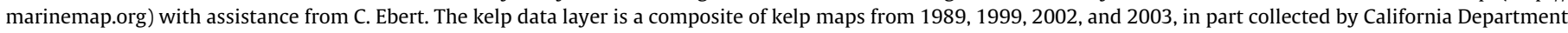

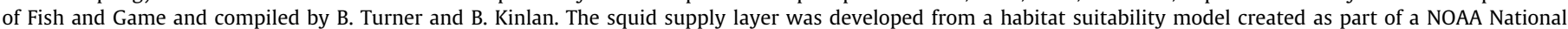

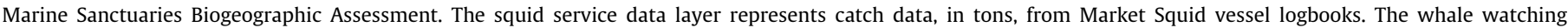

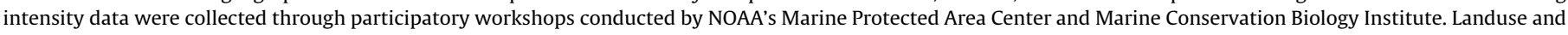

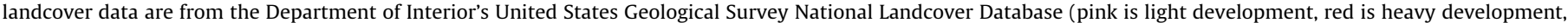
green is forest, and tan is all other land uses).

marshes, or seagrass beds is often presented as a shoreline protection service [8]. This process is often measured as the percentage of wave height attenuated, which helps quantify the potential amount of an ecosystem service. Without an adjacent human presence (Fig. 2d), however, this potential service remains only that, and does not provide any actual benefit. Thus percentage of wave height attenuated is an appropriate supply metric, but is not a sufficient metric of the service provided or its value.

Measuring supply is essential to ecosystem service assessments, but service provision is also determined by human "consumption" of the supply. In some cases, the placement and accessibility of human-built infrastructure and the spatial distribution of people and ecosystems enable humans to interact directly with the ecosystem in ways that turn the supply into a service that is "consumed" through active use, passive experience, or some other type of connection. In the case of shoreline protection, it matters where people and their property are located relative to the habitats and processes that provide protection (Fig. 2d). In other cases, like the provision of wave energy, the location of human-built infrastructure (e.g., conversion facilities, transmission lines) affects people's ability to consume the service. Without this information the potential of an ecosystem to provide benefits to society (supply) can be represented, but nothing is revealed about how much of a service is actually being delivered to people. Reporting in supply terms will often lead to overestimation of the benefits people receive from ecosystems and marine spatial plans based on supply measures alone will leave the drawing board with inflated expectations and, likely, a lower chance of success. For example, the abundance of fish (the supply) can be high around small island nations. Actual harvest (the service) is usually a small fraction of the total stock abundance, however, because these fleets are dominated by small boats that cannot reach offshore stocks. Distinguishing between supply and service metrics provides more accurate information about the ecosystem services affected by management decisions and enables better prediction of the consequences of those decisions for a broad range of social benefits.

It is also important to include people's preferences for different services when making decisions that involve tradeoffs. Different places may receive the same amount of service but the value of 
the service, private or social, may vary. Consider Atlantic cod and Atlantic croaker. These two species provided a similar amount of service in the United States in 2008 (8652 and 8513 metric tons landed, respectively), but cod had a much higher total market value $(\$ 30,635,000$ vs. $\$ 8,695,000)$ [9]. This example uses market revenue as a measure of gross economic value, but non-market, non-use, and future or potential values also can be represented in value metrics. The two species also support important recreational fisheries, for example, with Atlantic croaker generating much higher levels of non-market harvest than Atlantic cod. This higher amount of service may not carry over to a higher value, however, if fishermen consider Atlantic cod to be a more valuable fishing experience. And finally, even values that lie outside the economic realm can have a role in assessing ecosystem services. Storm surge may have greater impacts on communities where people are less likely to escape flooding, such as indigenous groups or the poor [10]. Reporting the value of coastal inundation control only in economic terms would miss social policy goals of protecting such communities. Identifying who gains and loses provides a more complete picture of the service's value. Marine spatial plans that use value metrics can provide important insights into tradeoffs that involve economic and social benefits and costs.

\section{Ecosystem supply and services near San Francisco Bay, California}

To demonstrate how the choice of metrics can substantially change our view of the ocean, consider the coastline near San Francisco Bay, California (Fig. 2a), home to many fisheries, wildlife viewing, commercial shipping traffic, a National Marine Sanctuary, and active real estate and agricultural industries, among other uses. Focusing on supply metrics (Fig. 2a and c) instead of service metrics (Fig. 2b and d) could mislead management decisions and generate unnecessary conflicts among stakeholders. Looking at property protection from inundation (Fig. 2c; approximated by kelp presence), squid availability for harvest (Fig. 2a; measured by squid habitat suitability), and wildlife viewing opportunities (Fig. 2a; approximated by whale sitings) gives a picture of extensive and relatively uniform supply of these features and processes in this region. Such information provides little guidance on where these supplies manifest themselves as actual services. Service metrics for these three services (measured by kelp occurrence adjacent to human property, the spatial distribution of squid harvests, and the spatial distribution of whale boat visitation intensity) show a much more variable seascape and emphasize where people benefit. For example a conservation area placed along the coast near the town of Bolinas (red area in Fig. 2c and d) could have a greater positive impact on ecosystem services than one placed further north along the coast, even though the northern coast has much more extensive kelp beds and higher supply. Further, incorporating value metrics such as squid ex vessel revenue, costs of avoided damages from property protection, and whale-watching revenues could better inform management, clarifying where conflicts are likely to be most contentious and identifying management options that will benefit the most people. Although this heuristic example is incomplete, it demonstrates how using service metrics allows the comparison of "apples to apples" rather than "apples to oranges" in terms of the benefits people receive from the ocean.

\section{Conclusions}

Society is looking to the oceans to serve its needs in more and bigger ways, adding plans for alternative energy solutions and more food production to the list of already intensive demands. MSP has emerged as an important tool to conserve and wisely use the rich bounty they provide. Right now, the scientific capability exists to develop spatial plans that consider how people benefit from ecosystem services and to incorporate service metrics into policy. Scientists must continue to work closely with decision-makers and stakeholders, however, to develop the social, economic, and ecological information needed for quickly and clearly identifying appropriate service metrics. Without ways to accurately measure ecosystem services and compare them using a common language, MSP could bog down, creating unnecessary conflicts, unintended consequences, and impossible promises. The approach presented here provides a straightforward way to be clear about the things society values and how to measure them so that rapid progress can be made towards the successful implementation of MSP.

\section{Acknowledgments}

The ideas in this paper benefited from a workshop facilitated by the Communication Partnership for Science and the Sea (COMPASS), the Natural Capital Project (Stanford University, The University of Minnesota, The Nature Conservancy, World Wildlife Fund), and Ocean Analytics (UCSB). Funding was provided by COMPASS, predominantly from the David and Lucile Packard Foundation. Funding and ideas were also provided by the California Current Ecosystem-Based Management Initiative, led by COMPASS and University of California, Santa Cruz, with funding from the David and Lucile Packard Foundation and the Gordon and Betty Moore Foundation. This manuscript was improved by comments from K. Arkema and C. English.

\section{References}

[1] Mims C, Schupak A, Moyer M, Simpson S, Pavlus J, et al. Word changing ideas: 20 ways to build a cleaner, healthier, smarter world. Scientific American; 2009.

[2] Obama B. National policy for the oceans, our coasts, and the Great Lakes. Memorandum 2009, 〈http://www.whitehouse.gov/assets/documents/ 2009ocean_mem_rel.pdf $\rangle$.

[3] White House Council on Environmental Quality. Final recommendations of the Interagency Ocean Policy Task Force. Washington, DC: White House; 2010.

[4] Pew Oceans Commission. America's living ocean: charting a course for sea change. Washington, DC: Pew Trusts; 2003.

[5] U.S. Commission on Ocean Policy. An ocean blueprint for the twenty-first century. Final Report, Washington, DC, 2004.

[6] UNESCO. Marine Spatial Planning Initiative, 〈http://www.unesco-iocmarinesp.be/> (accessed January 2011).

[7] Millennium ecosystem assessment. Washington, DC: Island Press; 2005.

[8] Barbier E, Koch EW, Silliman BR, Hacker SD, Wolanski E, et al. Coastal ecosystem-based management with nonlinear ecological functions and values. Science 2008;319:321.

[9] Pritchard ES. Fisheries of the United States. Silver Spring: National Marine Fishery Service Office of Science and Technology; 2008.

[10] Brouwer R, Akter S, Brander L, Haque E. Socioeconomic vulnerability and adaptation to environmental risk: a case study of climate change and flooding in Bangladesh. Risk Analysis 2007;27:313. 